\title{
Justification for Remote Control of Construction and Road-Making Machines
}

\author{
Nadegda Savelyevna Sevryugina ${ }^{1}$, Eugene Alexandrovich Volkov ${ }^{1} \&$ Eugene Pavlovich Litovchenko ${ }^{1}$ \\ ${ }^{1}$ Belgorod State Shukhov Technological University, Belgorod, Russia \\ Correspondence: Nadegda Savelyevna Sevryugina, Belgorod State Shukhov Technological University, \\ Kostykova Street, 46, 308012, Belgorod, Russia. E-mail: ujinisthebigwolf@yandex.ru
}

Received: July 3, $2014 \quad$ Accepted: July 16, $2014 \quad$ Online Published: September 1, 2014

doi:10.5539/mas.v8n5p179 URL: http://dx.doi.org/10.5539/mas.v8n5p179

\begin{abstract}
It is evident from the experience of operating the construction machinery (excavators, bulldozers, loaders etc.) that quite often the machinery and its operators are working under severe conditions. Working under threat of rock fall, on unstable or contaminated grounds, or debris handling tends to increase the impact of adverse occupational environment on the operators' health. When the operators are at risk, it is advisable to deploy remote process control technologies on the work sites. This is what brings research and development of modern remote control systems to the top of the chart in order to improve the productivity of machinery, enhance the safety and quality of the jobs carried out. The use of remote control will exclude the adverse impact of aggressive environment during the process operations. The research allowed to establish that the design specifics of the construction and road-making machines enable them to go far beyond the standard process layout giving into a much wider range of application, up to aggressive environments. A crawler excavator model was devised, imitating the visibility range of the process areas for the manual and remote control systems. Implementation of remote control for construction and road-making machines may become a step towards a completely new level of interaction within the man-machine-environment system.
\end{abstract}

Keywords: aggressive environment, elimination, machine, safety, control system

\section{Introduction}

The designers developing modern construction and road-making machinery have to take into account a variety of functionality indices determined by psychophysical capabilities of operators, to ensure efficient and safe operation within the man-machine-environment system.

It is due to the fact that, as long the industry development intensifies and new machinery is conceived, the operators's activity is becoming increasingly complex and subject to stresses. The functional specifications of construction and road-making machinery do not at all times meet the requirements of the sites where it is operated. This results in deployment of substandard process layouts, which, in turn, leads to impaired efficiency and increased labor consumption (Khmara and Shatov 2012; Romanovich and Kharlamov, 2009). Such production sites feature specific operational conditions, whether natural and climatic or due to the highest level of man-made impact. Ensuring quality and safety of the operational tasks under such conditions becomes a real challenge, and the environment conditions set thresholds for the operator's work. On great many occasions, when the personnel's actions prove to be wrong, it is not due to poor skill level (though the there are many problems on this side as well) but to the mismatch between the machinery's design features and human capabilities (Scopylatov \& Yefremov, 2013). The physical environment of the production site has to correlate with the human performance features, and only then one can expect high productivity from him/her (Munipov \& Zinchenko, 2001). Certain conditions demand from operators to use their psychophysical capabilities to the utmost extent, which, under adverse operational environment, may provoke erroneous actions, resulting not from poor skill level but from the mismatch between the machinery's design features and the operational environment, on the one side, and human capabilities.

Adverse factors in the operational environment provoke occupational diseases of operators, often resulting in permanent disability (Poroznuk et al., 2012). The operators of construction and road-making machinery are subjected to continuous vibration loads, noises, and dust, which can give rise to hand-arm vibration syndrome, hearing disturbances, diseases of peripheral nervous system, locomotor and respiratory diseases. Unfortunately, 
the design of modern digging and road-making machinery fails to ensure protection of operators from adverse factors caused both by operational environment and the machines (Zorin et al., 2009).

A wide range of operational tasks require to limit the presence of operators on the production site (Kajita et al., 2006). Listed below are examples of construction and road-making machinery operation involving increased adverse effects:

- mining and concentrating mills, mines, ore dressing mills, open pits for commonly occurring minerals, construction material works;

- animal burial sites (anthrax);

- waste dumps, sanitary landfills for solid household waste and toxic chemicals;

- demolition of buildings and debris handling;

- mitigation of radiation accidents and incidents involving detection of uncontrolled radiation sources.

Various transport, digging, filling, compacting, and crushing machinery is used at the above sites, all subjected to aggressive environment and quickly going out of service.

If we consider a specific machine as a complex unit of equipment, the principal natural, climatic, and environmental factors produce the following impact on it:

- High temperature: reduced viscosity and modified structure of diesel fuel, lubricants, pressure and process fluids, impaired cooling of internal combustion engines, accelerated ageing of rubber seals and other insulating materials.

- Low temperature: increased viscosity of diesel fuel, congealed lubrication oils and solid greases, frozen condensate in pneumatic systems, reduced toughness of steels, hardened and embrittled rubber seals.

- Increased humidity: accelerated corrosion of steel parts, reduced insulation resistance, water intrusion into fuel and process liquids, mold build-ups.

- Reduced humidity: thickening lubrication oils, drying out seals, fracturing insulation materials.

- Sun radiation: changing coefficient of friction for friction materials, accelerated ageing of polymer coatings.

- Wind: drying of materials, increased heat output of machine parts and extra strain on them.

- Dust: changing coefficient of friction for friction materials, clogging of ducts and reduction of air flows, impaired cooling and ventilation, build-up on heated surfaces reduces heat exchange, and intensely heated items may become a source of ignition.

- Aggressive environment: accelerated deterioration of materials. The following groups of environments is among the most widespread: potent oxidizers (nitric, chromic acids etc.); mineral and organic acids (phosphoric, acetic acids, etc.); alkali; organic compounds (petroleum products, etc.); halogen compounds. Aggressive environments can produce chemical transformation, deterioration, cracking, stiffening, etc.

Therefore, research of machinery operation and operators' activities within the single man-machine-environment system emphasizes the importance of finding new ways to reduce the risk of human errors and enhanced operational safety of construction and road-making machinery.

\section{Materials and Methods}

Working under complicated operational conditions relies on operation, upkeep, and maintenance costs of machinery. If insufficient capacity, inappropriate or unreliable equipment is selected, early failures may occur which, under urgent work pressure, may prove to be critical.

Special operational conditions for machinery are accounted for at the stage of design and manufacture. Modern equipment is manufactured in various climatic options as regards their fitness for operation in various macroclimatic zones: for cold, moderate, arid, or humid tropical climate. Standard machinery greatly outnumbers the specialized options, which is due to overwhelming proportion of brown field areas with moderate climate, as well as to manufacturing industrial facilities, production cost of machinery etc. In this connection, it is necessary to adapt standard machinery to special operational conditions by means of special refit and by changing their modes of operation (Karakulev et al., 1991). Such necessity arises during operation of standard machinery in climatic areas with high temperature fluctuations or when it is required to operate such machinery in a variety of meteorologic conditions (Kudryavtsev, 2006).

To adapt process systems to their operational conditions, proven methods are used to refit such systems, thus 
obtaining high efficiency of standard equipment under special conditions. The solutions improving the efficiency of machinery have to be coordinated against each factor affecting the productivity (purpose, operational environment, operating mode, technical condition, technologies deployed) and the duration of the machinery operation, as well as any possible variations of all these factors. Therefore, the aggregate range of impact for each specific factor builds into the set of positive/adverse factors affecting the productivity of process systems.

Analysis of the man-machine-environment system enables to suggest a way to reduce the impact of aggressive environment on such system:

- Develop a set of activities which have to include the selection and setup of specialized equipment;

- Remove the operator from the potential hazard area where the operations are carried out by implementing remote control;

- Comprehensive integration of technology to improve efficiency, safety, and enhance quality control of the processes and remake them into a single high added value production line.

This is what brings research and development of deploying modern remote control systems in construction and road making machinery to the top of the chart in order to improve the productivity of machinery, enhance the safety and quality control of the jobs carried out. There is a widespread solution for such tasks: a team of equipment enabling two operation modes, direct or remote, depending on the operational conditions (Michael, 2012; Martin, 2011).

\section{Informative Part}

1) Currently the electronic control systems of construction and road making machinery are monitoring and optimizing the operation of the engine, hydraulics, all sensors and operating controls, and ensure that information is shown on the display. The consistent operation of such electronic control systems is due to digital communication and control features applied. Operators may use the electronic control system to adjust the operating force and receive feedback about the condition of and load on such machinery resulting from interaction with the objects (Safford, 1973; Robert S. et al., 2002). Reliable feedback is ensured between the operator and equipment, to monitor the reaction force when actuators contact the working surface. The existing level of construction and road making machinery and the capabilities of radio electronic features enable creation of a set of radio devices which can be applied to provide remote control over operation of specialized machinery under a variety of conditions.

The capability to handle the necessary process operations is the key functionality for construction machinery remote control systems. It can only become possible subject to a fail-free control of the actuators of such machinery, which requires a homogeneity and optimization of operation for all units and modules. The construction machinery control system operation can divide into the following tasks:

a) Principal: a set of control features to carry out the machinery operational cycle (its core function).

b) Auxiliary: a set of auxiliary features enabling control between the operational cycles.

c) Visual and spatial control of process operations. A system of cameras, microphones, positioning sensors, and data from the electronic control console enables visualization of parameters and positioning of the machinery and of the working members of its actuators.

The remote control system must be capable to handle the above tasks. At the same time, it must ensure feedback regarding the force impacting each of the actuators.

The coordination between the operations of such machinery can be ensured using the Master-Slave system already widely spread in modern construction equipment (Hirabayashi, 2006).

A typical Master-Slave system is a team of coordinated devices consisting of the following systems:

Master: controls one or several other devices (servo units).

Slave: is set up to operate under control, ensuring that the operating forces are applied consistently with the gearing diagrams of the operational equipment and using the installed feedback system, and features a set of information features to ensure detection of mechanical loads during the operations.

Master-Slave system enables control of motions of working members and sends signals describing such motions of each working member, enabling their realtime positioning (Hirabayashi, 2006). Feedback ensures adequate effect, based on the force applied by the operational equipment to the working surfaces. Such interaction ensures the degree of "sensitivity" between the components of the man-machine-environment system, thus promoting the process quality. 
Also, there are a wide variety of remote controllers for construction and road-making machines. Examples are listed in the following patents (US №6219589B1/2001, EP №0976879B1/2006, US №5448479/1995, US №6907029B2/2005, WO №691395A2/2008, WO №078811A1/2002, US №7890235B2/2011, US № $8272467 \mathrm{~B} 1 / 2012)$. Common feature in the present inventions is the using the remote control unit or organized remote stationary point for the remote control.
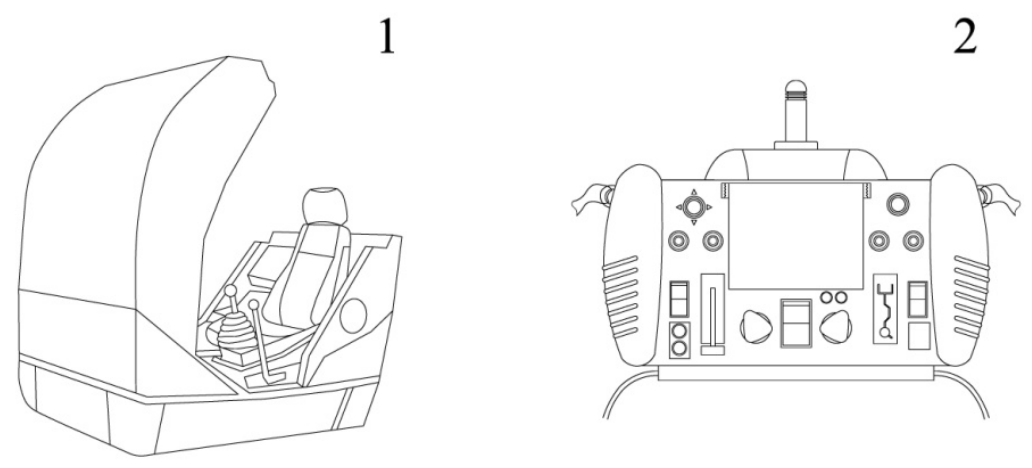

Figure 1. Remote controllers for construction and road-making machines: 1 . the remote stationary point for the remote control; 2. the remote control unit

2) Generally speaking, the proposed modern single-purpose remote control systems for construction machinery operate as follows (fig. 2.): The electronic control unit 1 gathers (detects) and generates a control command uk1(t) based on the inputs and source information $\mathrm{e}(\mathrm{t})$ about the condition of the controlled equipment 3 taking into consideration the feedback channel 4 data. Then formed information uk1(t) is supplied to the control channel 2 , the operation of which is determined by radio RC, or laser channel LC. The control channel 2 is determined by the corresponding output data $\mathrm{uk} 2(\mathrm{t})$. Then commands are transmitted to the control object 3 . As a consequence arising from this distortion e1(t), the information $\mathrm{uk2}(\mathrm{t})$ comes to the object may be slightly different from uk1( $\mathrm{t}$ ) Signals in the facility management are also affected the possibility of distortion e2(t). The feedback channel 4 detects adequate effect, based on the force applied by the control object 3 to the working surfaces, and returns the operational data to the electronic control unit 1.

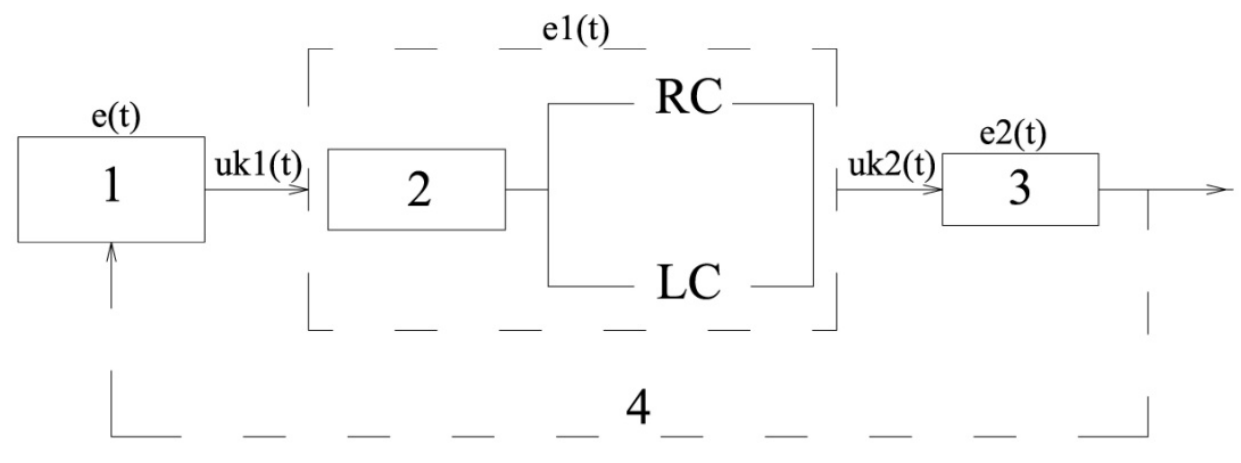

Figure 2. The scheme of a remote control system of construction machines

The necessity to use a wide radio frequency range to ensure a reliable communication channel without cross distortion or jamming, is a serious drawback of remote control systems. The operational conditions may impose limitations on the radio channel if side electronic noises are present (Ustinov et al., 2006).

3) To assess the ergonomic features created by application of construction machinery remote control, a 3D model of a crawler excavator using SolidWorks CAD software. The range of visibility is one of important ergonomic features for any vehicle. The range of visibility means the excavator's design feature describing the objective possibility and conditions for the operator to perceive visual information information for a safe and efficient control of the vehicle. To this end, the visibility diagrams were drawn for various operational conditions and 
means of control (manual or remote) for such machinery.

Based on orthogonal drawings of the excavator, a 3D model is built based on the following list of parameters: viewing angle, eye transition and staring time, visibility sector. The principal visibility range indicator is the distribution of attention between the preferred and occasional surveillance items.

- the preferred surveillance items include: operational positions of the shovel, shovel boom, levees, vehicles etc.;

- the occasional surveillance items include: tracks, control console, information panels etc.

And to carry out the visibility range for the excavator under two control modes, visibility diagrams were drawn for civil structure dismantling. Dismantling a building in cities with an excavator is a widespread practice, as certain other controlled demolition techniques (such as pinpoint blast) sometimes are impossible to use. In this case the process visualization for different types of control will enable to feel the difference between the conditions of the two control modes (Volkov, 2013).

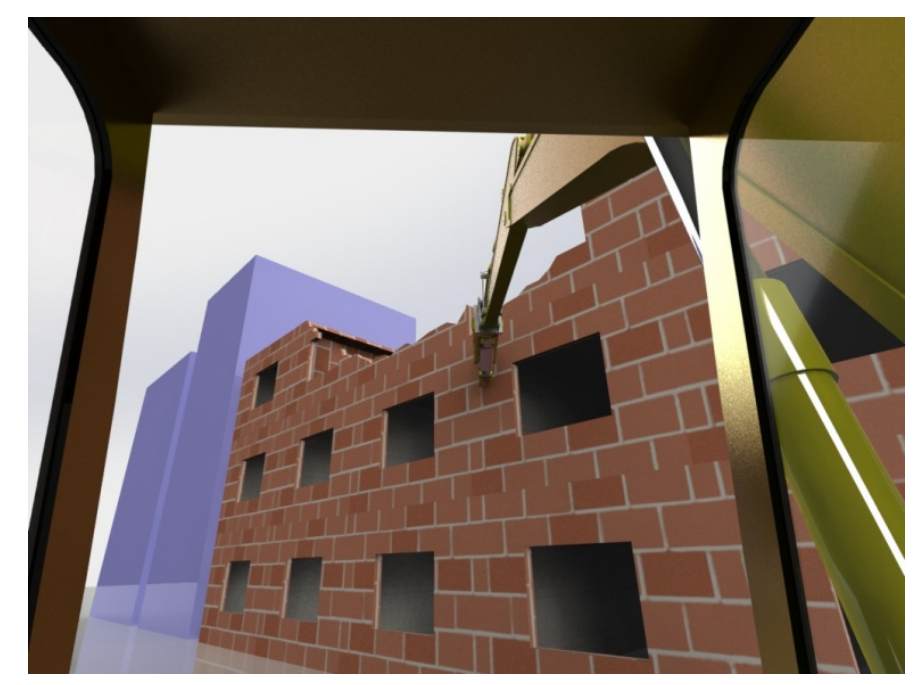

Figure 3. Process visibility from the excavator cabin

Inside the excavator cabin, a virtual point is selected to model the operator's glance, the visibility degree from the workplace will depend on the position of the cabin and operator's seat inside it, design of window apertures and quality of glasses and mirrors; it is also necessary to account for the possibility for the operator to change the position of his/her torso (e.g. upfront or leaning forward).

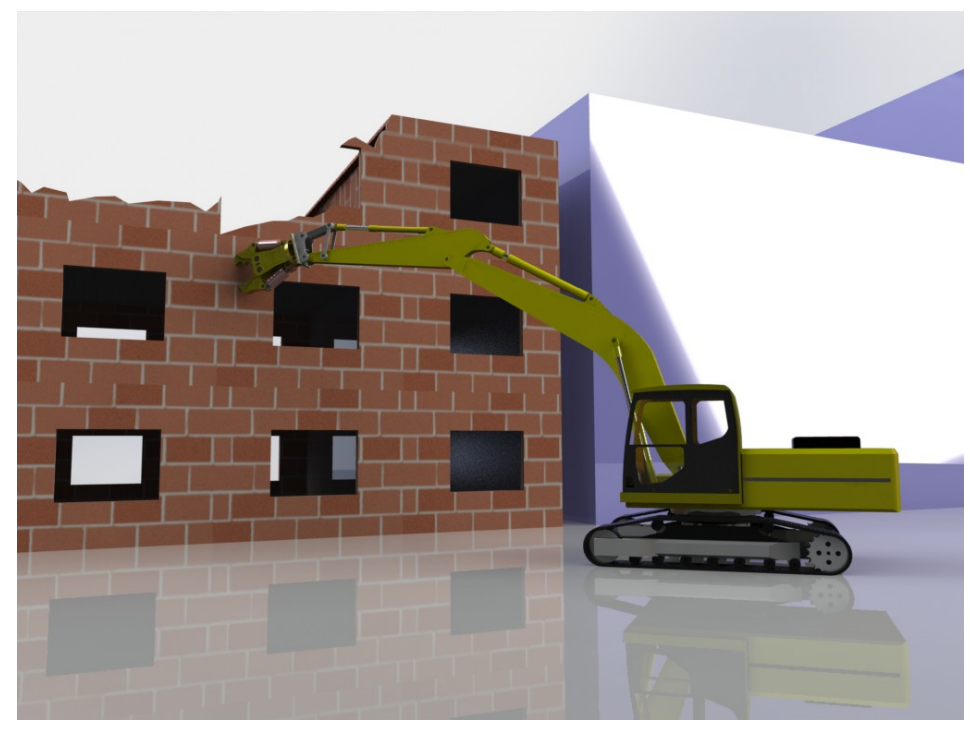

Figure 4. Process visibility from the remote control point 
The remote control system grants a freedom of choice for the remote control point, thus enabling the operator to select both a convenient and safe position from which visual monitoring over the process operations is possible.

Therefore, the visibility diagrams enable to assess the adequate visibility of the preferred and occasional surveillance items under different control modes. The operator using remote control is able to continuously monitor the changing conditions of the working area and give a more substantiated judgment on such factors as safety and quality of work, thus improving the efficiency of the machinery operation. The working area image can be delivered using 3D models or with extra cameras and data read from computers, which, in turn, enhances the possibilities to monitor the process system as a whole (Steven \& Curtis, 2012; CMT, 2013).

\section{Discusission}

We established that the design specifics of the construction and road-making machines enable them to go far beyond the standard process layout giving into a much wider range of application, up to aggressive and hazardous environments. Such conditions may become incompatible with the normal psychophysical loads on construction machinery operators, resulting in a variety of adverse effects. There are modern examples of successful deployment of remote control over machinery. In 2010 Brodrene Gjermundshaug Anlegg AS. was busy reclaiming the territory of a former military firing range on the territory of the actual Dovre National Park (Norway). The hazard consisted in the occurrence of many unexploded shells in the ground. One of the operators, Havard Thoressen, said: "It was quite a strange bit of experience, learning to do my normal job sitting in a steel box miles away from the place I am actually working at. It took me about two weeks to get used to the new way of working. First we had some difficulties to retain control over everything, but now there are no more problems" [CM, 2010]. This is the justification for remote control system implementation in operation of construction and road-making machines in aggressive environments, to reduce psychophysical loads on the operators and enhance their safety.

\section{Consclusion}

Operational and design are the two types of requirements applied to the construction machinery remote control systems.

Operational requirements consist in fail-safe and reliable operation of all remote control systems under the given weather and climatic conditions. The importance of this condition is due to the fact that the current development of equipment mostly targets its improved precision and implementation into control systems of high speed computers assuming an increasing amount of the operators' functions. Such control systems are complex and contain many different components. Whereas a failure of any single component may disturb the operation of the entire system, it is, therefore, of utmost importance that all components and the system as a whole should be highly reliable [Bogomolov, 2008].

Design requirements consist in quality of the installed features' operation. It must have minimal dimensions and weight, resist overloads, and be immune to vibration. These features should be operable under a wide range of temperatures, humidity, and pressure.

Remote control features fitted on the construction machinery will increase its base cost up to $30 \%$. Taking into account the process operations carried out by the machinery and the conditions of such operation, the development of remote control sets for such machinery must be based on the value added. This consideration is viable both to design new machinery and to retrofit the existing equipment. For the latter, to avoid excessive costs, onboard equipment may be installed without any material redesign of the machinery. The consideration of extra costs is overshadowed by the totally different level of safety and comfort offered by the remote control systems.

At this stage of the research we established that the design specifics of the construction and road-making machines enable them to go far beyond the standard process layout giving into a much wider range of application, up to aggressive and hazardous environments. Such conditions may become incompatible with the normal psychophysical loads on construction machinery operators, resulting in a variety of adverse effects. Justification was provided for remote control system implementation in operation of construction and road-making machines in aggressive environments, to reduce psychophysical loads on the operators and enhance their safety.

Further research will focus on the technical aspects of the project safe and effective system of remote control of Construction and Road-Making Machines. 


\section{References}

Bogomolov, A. A. (2008). Technical bases of creation of machines. Belgorod: BSTU named after V.G. Shukhov. Cat Mining Tecnology. Retrieved July 5, 2013, from https://mining.cat.com/miningtechnology.

Hirabayashi T. (2006). Name lost. KENSETSU KIKAI Magazine, 42(6), 27-32.

Kajita Shigeo, Awano Katsusuke, Tozawa Shoji, Nishikawa Hiroyasu. Remote radio operating system, and remote operating apparatus, mobile relay station and radio mobile working machine. Patent No.: EP 0976 879 B1. Date of a Patent: 20.12.2006.

Karakulev, A.V., Ilyin, M. W., \& Markelanec, O. V. (1991). Operation and construction of working equipment and machines. Moscow: Transport.

Khmara, L. A., \& Shatov. S. V. (2012). Determination of mechanization for demolition of ruined buildings on the basis of dam structure analysis. Mechanization in construction, 1, 34-38.

Kudryavtsev, E. M. (2006). Complex mechanization of construction (p. 424). Moscow: Publishing house of the Association of civil engineering universities.

Martin Carlsson. Control system for a remote control work machine. Patent No.: US 2011/0282519 A1. Date of a Patent: Nov, 17.2011.

Munipov, V. M., \& Zinchenko, V. P. (2001). Bases of ergonomics. Moscow: Logos.

Poroznuk, L. A., Vasylenko, V. A., \& Poroznuk, E. C. (2012). Role of environmental audit in the waste management in the Belgorod region (pp. 177-180). Vestnik of the University (issue 4), BSTU named after V.G. Shukhov.

Robert S., James M,. Leif A. Remote Control System. Patent No.: WO 02/061515 A2. Date of a Patent: Jan, 29.2002.

Romanovich, A. A., \&. Kharlamov, E. V. (2009). Technical maintenance of construction machines. Belgorod: BSTU named after V.G. Shukhov.

Scopylatov I. A., \& Yefremov O. Y. Personnel management. Bibliotekar.ru. Retrieved January 18, 2013 from www.bibliotekar.ru/biznes-33/24

Safford, Edward Zenfesty. Radio control manual / S.E.Zenfesty VII, 192 p.p., ill., 1.25 sh «Brif Nat. Bibliogr.» 1973. - Slough: Fonlskam, 1973. -№ 1231: 19.

Steven E. Nielsen, Curtis Chambers. Virtual white lines for delimiting planned excavation sites. Patent No.: US8, 218,827 B2. Date of a Patent: Jul, 10.2012.

Ustinov, U. F., Teplyakov, I. M., Cononov, A. A., \& Avdeev, U. V. (2006). The problem of constructing remote control systems for construction machines. Universities's news, 1, 83-86.

Volkov, E. A. (2013). Study of ergonomic technological perfomance machines, as a factor in assessing the effectiveness of system "man-machine-environment". Industrial safety journal, 6, 32-34.

Zorin, V. A., Daugelo, V. A., \& Sevrjugina, N. C. (2009). Safety requirements to ground-based transport systems. Belgorod: BSTU named. V.G. Shukhov.

CAT Magazine Issue. (2010). Shaping the future by remote control. Date Views. Retrieved September 14, 2012, from http://mining.cat.com/miningtechnology

Michael A. Staab. (2012). Remotely controlled backhoe. Patent No.: US8,272,467 B1. Date of a Patent: Sep, 25.2012 .

\section{Copyrights}

Copyright for this article is retained by the author(s), with first publication rights granted to the journal.

This is an open-access article distributed under the terms and conditions of the Creative Commons Attribution license (http://creativecommons.org/licenses/by/3.0/). 